\title{
Architecture, Engineering, and Construction Interdisciplinary Senior Inter- disciplinary Project Educational Model
}

Dr. Jinsung Cho, California State Polytechnic University Pomona

My name is Jinsung Cho, an assistant professor of Civil Engineering Department in California State Polytechnic University Pomona. I have had more than 18 years in both academia and Civil and Construction Industry. My specialty is the behavior of underground infrastructure, Trenchless and Tunneling Technology, as well as 3D Virtual Construction Design \& Management. I am a reviewer or member of several professional organizations, such as ASCE, NASTT, and ASC.

\section{Dr. Giuseppe Lomiento, California State Polytechnic University Pomona}

Giuseppe Lomiento is Assistant Professor in the Civil Engineering Department at Cal Poly Pomona. He holds a Master Degree and PhD in Structural Engineering from the Sapienza University of Rome. Prior to joining Cal Poly, he was Project Scientist in the Structural Engineering Department at UC San Diego. His research focuses on earthquake engineering, structural monitoring, and multi-physics analysis. As a Professional Engineer, he has been involved in the analysis, design, and testing of a number of civil engineering structures, including bridges, hospital facilities, recreational facilities, and shipping piers. He is member of the American Concrete Institue (ACI), the Structural Engineers Association of Southern California (SEAOSC), and the International Society for Structural Health Monitoring of Intelligent Infrastructure (ISHMII).

\section{Dr. Gad M. Ghada, California State Polytechnic University, Pomona}

Dr. Ghada Gad is an Assistant Professor in the Civil Engineering Department at Cal Poly Pomona. She received her $\mathrm{PhD}$ in Civil Engineering (Construction emphasis), from Iowa State University. Her main areas of research is in construction management focusing on contracts, procurement, project delivery methods, estimating, and risk management, in addition to the cultural aspects of construction projects. She is also an ExCEED fellow; her teaching pedagogy focuses on adopting active learning techniques in her classes, to increase student attainment and motivation beyond the classroom.

\section{Ms. Katrin Terstegen, Cal Poly Pomona}

Katrin Terstegen is an Assistant Professor in the Department of Architecture at California State Polytechnic University, Pomona, where she teaches architectural design studios, as well as seminars with focus on materials.

She was a Senior Associate for JOHNSTONMARKLEE in Los Angeles for ten years and now has her own practice, KATRINTERSTEGEN. She also worked for various international architecture firms, including Decq \& Cornette in Paris, M3H in Amsterdam, and Pugh+Scarpa in Santa Monica.

Katrin received her Diploma of Architecture (Masters of Architecture) from the Technical University Berlin in 2002 and her Diploma of Architecture/RIBA Part I+II from the University of Westminster in London in 1999. She also attended the Escola Tècnica Superior d'Arquitectura de Barcelona (ETSAB) from 1996-97.

In addition to serving as guest critic at various international schools, including the University of Hong Kong, Woodbury University, and the Southern California Institute of Architecture (SciArc), she taught at the Technical University Berlin, the University of Auckland in New Zealand, and the University of California, Los Angeles (UCLA).

Katrin joined the Department of Architecture at California State Polytechnic University, Pomona, in 2014. 


\title{
Architecture, Engineering, and Construction Interdisciplinary Senior Project Educational Model
}

\begin{abstract}
This paper presents a new educational model, developed in Cal Poly Pomona, in a senior project to provide students in Architecture, Civil, and Construction Engineering, a full-rounded professional experience, in line with contemporary trends of various disciplines' integration in the construction industry. The main objective of the proposed model was to foster the potential benefits that arises from shared educational goals between different technical areas. Through coordination with an existing Architectural class, the project involved students in Architecture, Civil Engineering, and Construction Engineering. The senior project mimics an Integrated Project Delivery process that simulates the complete development of a commercial building, from conceptual design to construction. Architecture students led the first phase of the conceptual design of the project, with Civil and Construction Engineering students setting constraints in term of structural efficiency, cost, and construction time. Engineering students then took the lead on developing the final design, and simulating construction by means of 4D (3D model + time) simulation software tools. Various assessment techniques, such as collaborative case studies, final project development, and perception surveys were used to assess the attainment of the model's educational objectives. Results of these assessment tools provides evidence that with such interdisciplinary experience, students develop an understanding of their roles, respective to other disciplines. It also fostered and enhanced communication among the three disciplines, allowing them to set common goals, and work collaboratively to achieve them.
\end{abstract}

\section{Introduction}

Conflicts and disputes are common on construction projects, and cause problems such as increased project costs, reduced productivity, and project delays, which could result in loss of profit or damage in business partnerships. Among the possible causes of such conflicts are contractual problems, behavioral problems, and technical problems. Contractual problems are usually related to delayed payments or unclear contractual terms, which transcend the mere technical aspects of the project execution. Technical subjects involved in the project, such as engineers and architects, are instead accountable for behavioral factors, such as the hesitancy to check for constructability, completeness of the technical documentation, and poor communication among project team members. Delayed instructions from architect or engineer are also technical problems that could cause possible conflicts with the contractor.

Design Build (DB) and Integrated Project Delivery (IPD) methods are increasingly been adopted in the construction industry, with the purpose of improving interactions between all different parties involved in the project into a process that collaboratively integrates the abilities and perspectives of all participants. This would ultimately lead to enhancing project results and maximizing efficiency throughout all phases of design and construction [1]. DB, specifically, has experienced increasing popularity in the construction industry ultimately for its recognized benefits, including overall reduction of project cost and completion time, compared to traditional 
Design Bid Build (DBB) Project Delivery Methods (PDMs). The major differences between DB and DBB is that in a traditional DBB, owner first hires an architect to develop the architectural design, and engineers to develop structural, electrical, mechanical, and plumbing plans, and specifications. The project is, then issued for bid to hire a general contractor, usually using a competitive low bid procurement process. However, this system has often proven to develop adversarial relationships among the project participants, majorly attributed to the lack of contractor's input in the design process, leading to change orders. Since the design process is completed with no contractor input, the probability of disputes deriving from behavioral and technical problems is significantly high. As for DB, the owner hires one single entity that serves as both the contractor and designer, allowing a single point of responsibility, contractor's early involvement in design, and faster delivery [2, 3]. This setting dictates, though, a new set of skills that needs to be acquired by both engineers and contractors due to the change in their typical standard roles.

With the evolving nature of the construction industry, there is yet still limited research directly focusing on investigating the interaction of students from different technical areas during their college education, and on fostering a collaborative environment, which could prepare future professionals for the increasingly high level of interaction required by the industry. This paper, thus, aims at fostering the understanding between architecture, civil and construction engineering students during their senior year through a DB collaborative project experience. The project was designed to allow students to experience and simulate a true project from award until delivery, and most importantly provide them a reality check of what they will face when venturing into this evolving construction market. The paper will start with a brief summary of relevant work, followed by the methodology employed, then the results and conclusions.

\section{Previous Research}

A few examples has been cited in literature on multidisciplinary learning models related to architecture and engineering students. For example, Rangel et al. [4] implemented the IPD methodology in lectures and architecture studio classes, in order to achieve more efficient learning performance. The collaborative curriculum and co-work between architecture and civil engineering students showed significant improvement in students' grade compared to the previous year. Students learned to understand the function of each discipline from the various design stages to construction process, which made them more motivated about their project. This collaborative class shows a good example of how IPD concepts could help to develop education [4].

Another model by Solnosky et al. [5] encompassed a 3-year multidisciplinary team pilot project program, including structural, mechanical, lighting/electrical, and construction engineering disciplines. The program was conducted in an Architecture Studio Class with help of experts from structure, MEP, and construction industry. The 3-year pilot class helped students to clearly comprehend the role of each discipline and their learning curve of understanding each discipline's role in building projects was tremendously improved as proven by survey results. The article also found that the integrated multidisciplinary collaboration education could produce great technical learning depth of what the industry needs [5].

These two collaborative education models demonstrate the great value of the interdisciplinary learning environment within AEC education. Our proposed education model, however, builds on 
the proven value of interdisciplinary learning, by proposing a model that integrates three different disciplines (Architecture, Civil, and Construction Engineering) into a fully rounded professional experience that mimics a real-life construction project, in line with contemporary trends of disciplines' integration in the industry, with constraints set from conception to delivery. It takes it further by using assessment tools to evaluate, not only the student knowledge about the various disciplines, but also by monitoring students' change in perceptions about the roles and responsibilities of the various disciplines, including their own roles.

\section{Methodology}

The proposed educational model consists of a thread developed in the Civil Engineering (CE) Curriculum in order to integrate students from different technical areas. The thread consists of the combination of an existing Architectural course with a newly developed Senior Project experience. Through the overlap of the CE 491/492/493 civil engineering senior project sequence, the ETC 461/462 construction engineering senior project sequence, and the ARC 401/405L Architectural studio class, students from Architecture, Civil, and Construction Engineering are introduced to an interdisciplinary framework. The proposed project aimed at expanding the current effort of the CE Department at Cal Poly Pomona into offering interdisciplinary learning opportunities at the undergraduate level in an IPD project that fosters collaboration between students in the three technical areas. Through this project, 19 Architecture (A) students worked jointly with $12 \mathrm{CE}$ students and 8 Construction Engineering Technology (CET) students on interdisciplinary design teams. The teams were assigned a problem statement to develop the design, and simulate the construction of an assigned case study, specifically a museum building. The project was developed over three stages.

\section{Project Stage 1}

Architecture students led this first stage of the process, developing sixteen (16) architectural designs within constraints set by Civil Engineers in terms of structural/geotechnical design efficiency, and by Construction students in terms of construction feasibility, time, and cost. At the core of the Architectural class, there was the investigation of methods of repetition and variations, used as an organizational technique, and as means to maximize efficiency in the construction process. A contemporary art museum for a single artist, located on the Menil Campus in Houston, Texas, and assembled of precast concrete elements, served as testing ground to explore the opportunities and challenges of this approach. The studio conceived the museum as a single-story mat building, arranged as a matrix of indoor and outdoor spaces with a total area of 40,000 square feet (of which one third is outdoor space). The building typology of the mat allowed students to examine various types of grids and field conditions, and explore the possibility of a building as an open-ended organism. The studio used precast concrete construction as the primary construction method and studied this technique from a technical point of view, as well as under architectural and aesthetic considerations. This included examining the implications of modularity and seams, as well as materiality, specifically in the context of an art museum.

The choice of the construction methods was based on modularity: repetitious elements were precast, while unique moments in the architectural design, conceived as "deviations", could be cast-in-place. The constraint of a single story building allowed students to focus on one typology, both architecturally (in terms of organization and circulation), as well as structurally. Since this building typology, an expansive mat building with repetitious elements, was so closely linked with 
precast concrete assembly as method of construction, it was paramount to consider concept and structure from the beginning, in particular in regards to feasibility. This involved consideration of module sizes, re-usability of concrete forms, transportability, and altogether efficiency and feasibility. It also offered the perfect platform for collaboration between civil engineers, construction engineers, and architects who together had to negotiate the various aspects factoring into the project. While the goal of the studio was to make the project feasible from a construction point, it was also the ambition to make the means of construction (standardized precast concrete panels made of repetitive modules) legible on the exterior, and therefore part of the architectural expression of the building. In that sense, the type of construction became both the functional, as well as the aesthetic driver for the project. A technical panel composed of faculty and industry professionals evaluated the 16 projects. At the end of this stage, two projects were selected and taken to the next stage of development.

\section{Project Stage 2}

In the second stage, the project developed into a DB PDM method. This method leverages the talents and insights of all participants to optimize project results, increase value to the owner, reduce waste, and maximize efficiency through all phases of design and construction. CE and CET students, as well as the two architecture students that developed the selected projects were split into two teams, each team responsible for the completion of the design and construction. In this stage, the CE students were mostly in lead, and worked collaboratively with the CET students to accomplish $75 \%$ of the structural design. The CET students instructed a construction process to be followed and simulated in the $3^{\text {rd }}$ stage of the project.

\section{Project Stage 3}

In the third and final Quarter (CE 493 + ETC 462), the CE students complete the remaining 25\% of the structural design, while CET students simulate all remaining phases of construction. The simulation of construction operates by means of 4D Building Information Modeling (BIM) software. The 4D BIM software links 3D modeling of the construction site with schedule (time) constraints, and then with cost-related information. In the construction site simulation, the predicted duration of the construction is scaled down to match the duration of the school year. In each of the weekly meetings, the CET students update their CE counterparts about the state of advancement of the project, and set deadlines in order to meet the schedule. In this phase, the CE students are mostly involved in solving possible issues encountered during construction, such as design changes.

\section{Explanation of the Proposed Module Assessment Tools}

The general goal of these collaborations was to create mutual respect and understanding, as well as train students to look at projects from multiple perspectives, ultimately bringing architectural, structural, and construction ideas together to a coherent role. This means that the best architects understand structure as integral to architecture, not as a subordinate discipline, and that the best engineers understand spatial and architectural concepts and are striving to find an adequate structural response, not just the most cost-effective solution. The goal was to encourage the disciplines to collaborate from the beginning of a project in order to find solutions that are holistic and have been informed by multiple forces. The assessment tools include (1) instructors' observations of the challenges faced by the students, (2) instructors' evaluation of the students' products, and (3) surveys delivered to the students to monitor the evolution of the mutual perception of their roles during the project. 
Instructors' observations were a result of formal and informal discussions between the four instructors/advisors on the project, who represent the three disciplines of the students (architect, engineer, and contractor). Students' products were evaluated three times during the first stage of the project, through a collaborative Case Studies Report and Presentation, an Interim Conceptual Design Report and Presentation, and a Final Selection Report and Presentation. Surveys were designed to be administered in two cycles - once at the beginning of the project to report students' knowledge of each other's disciplines, as well as common perceptions, and the other cycle to review if knowledge and perception had changed.

\section{Results, Analysis, and Discussion}

The following sections will report results generated from the instructors' observations of the students' challenges, assessment of student work interaction and products delivered, as well as the students' perceptional survey (perceptions of Architecture, CE, and CET students of each other's disciplines and work responsibilities).

\section{Instructors' General Observations on Challenges Faced by the Students}

The project required students to face a number of challenges due to the time constraints and level of interaction required. Architecture students worked either in groups of two or, in most cases, individually, conceiving a total of sixteen projects. At the beginning of the project, Architecture students spent a week setting a conceptual direction for their projects and then were soon joined by students of the two other disciplines to continue with the development of the project. After the selection of the architectural designs, five weeks were spent for the preparation of the technical offer and fifteen weeks were required for the completion of the design and the construction simulation. The time frame of the project for the completion of the design and the construction simulation certainly does not represent a real-world schedule. Given the complexities of program and site, it typically requires more time for an architect to conceive a project from a functional and conceptual perspective before the involvement of engineers is warranted. The compressed time frame in the architectural studio, therefore, posed a few challenges. While the Architecture students needed time to conceptualize the project, the engineering students soon requested a definitive direction in order to be able to work on the projects. There were instances where projects were completely redesigned after a few weeks, and engineering students had to start all over. While this experience frustrated students, it was also a valuable learning experience and simulated real life, mirroring the cliché that architects continuously change their projects, while engineers want to fixate the project as soon as possible. Allowing students the exchange and insight into the other discipline's priorities will help students in the future to better understand each other, and to direct their efforts by being both more definitive and/or more flexible in their approach to work.

\section{Students' Products - Instructors' General Assessment}

The evaluation of the products produced by the students highlighted some interesting findings as pertains to the educational model developed. From an architectural perspective, there was a surprising variety of design directions, given the tight constraints set by the brief. Most schemes were based, in plan, on a grid or other regular arrangement, including point grids, tartan grids, and layouts based on parallel bays with regular spacing. Often projects used a particular component as the core precast element. In some cases, this was a concrete wall, in others, the focus was a column or concrete frame (articulated as post and beam or as a portal frame), yet others proposed entire precast concrete "rooms" as the core element. The rigor in the selection of grids and precast 
elements was the result of the early conversations between students from all disciplines and set the groundwork for the development of projects in precast concrete construction.

Example of positive interactions between students are here provided for the two selected projects, which best represent the process and the outcome: the "Mona Hatoum Institute" (MHI) by Peter Goodwin (A) in collaboration with Daniel Lin, Stephanie Ling, Jacob Zepeda (CE), and Hoa Pham (CET), and the "Rene Magritte Art Museum" (RMAM) by Trevor Kaufman (A) in collaboration with Abraham Mercado (CE) and Aneesh Sreedhar (CET).

As shown in Figure 1, the layout of the MHI project comprises a series of parallel walls, which are spaced 16' apart and enclose fifteen 160' long bays within which the museum program is laid out. The challenge was to both accommodate services (HVAC ducting) and to support the roof structure in an inconspicuous manner. As a solution, the team proposed using the walls to absorb both structure and services. The walls were designed as sandwiches, comprised of an inner structural layer, rough precast concrete wall sections that were sandwiched between two thin, precast concrete panels with finished surfaces. The hollow space in between was used for services. The main challenge of the project was a wall opening with a 128' span in the main gallery that, in order to maintain the desired head height, only allowed for a restricted 36” structural depth. The students discussed and reviewed several options, considering both architectural and structural implications. A concrete beam, which would have been true to the structural system, was rejected as an option, as it would have required more depth and would have interfered into the space. A column to reduce the span was not an acceptable option from a programmatic perspective. The engineering and architecture students then proposed a hybrid system, using a steel beam. Since the steel beam was hidden in between the concrete shells, this proposal created the illusion that the delicate outer shells spanned the whole distance, challenging our tectonic expectations.
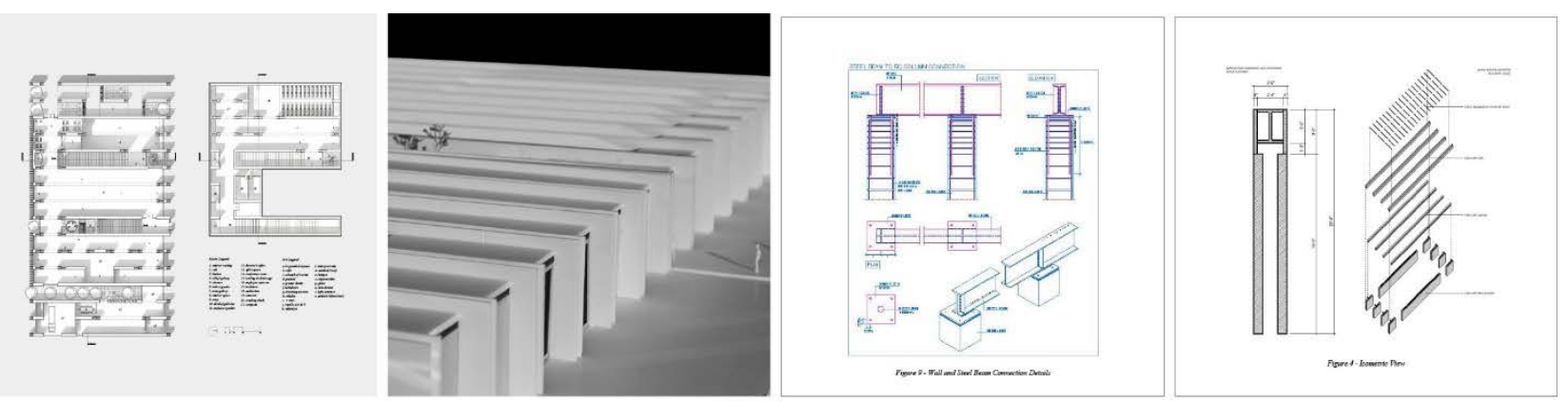

Figure 1: Student Project "Mona Hatoum Institute" (MHI)

Architectural Design (left images) and Structural Analysis (right images). Students: Peter Goodwin (A) / Daniel Lin, Stephanie Ling, Jacob Zepeda (CE), Hoa Pham (CET)

The RMAM project consists of five parallel vaults, each 256' long and 32' wide that form a roof over the entire project (Figure 2). The floor plan is organized in ten bays with both straight walls following the vaults' edges and curved walls, allowing for a diagonal uninterrupted circulation through the building. The challenge of the project was the off-site fabrication of the vaults. Due to their large size and challenges with delivery, it would be impractical to cast them off-site. The team of Architecture, CE, and CET students, thus, proposed a two-fold approach to the project components: vaults will be pre-cast on site and lifted by crane, and the two wall types (curved and straight) were standardized, so that off-site production was feasible. The chosen method also 
reflects the architectural language: the vaults were singular, non-repetitive designs, and consequently cast-in-place. The repetitive walls, in contrast, were modules that could be pre-cast.
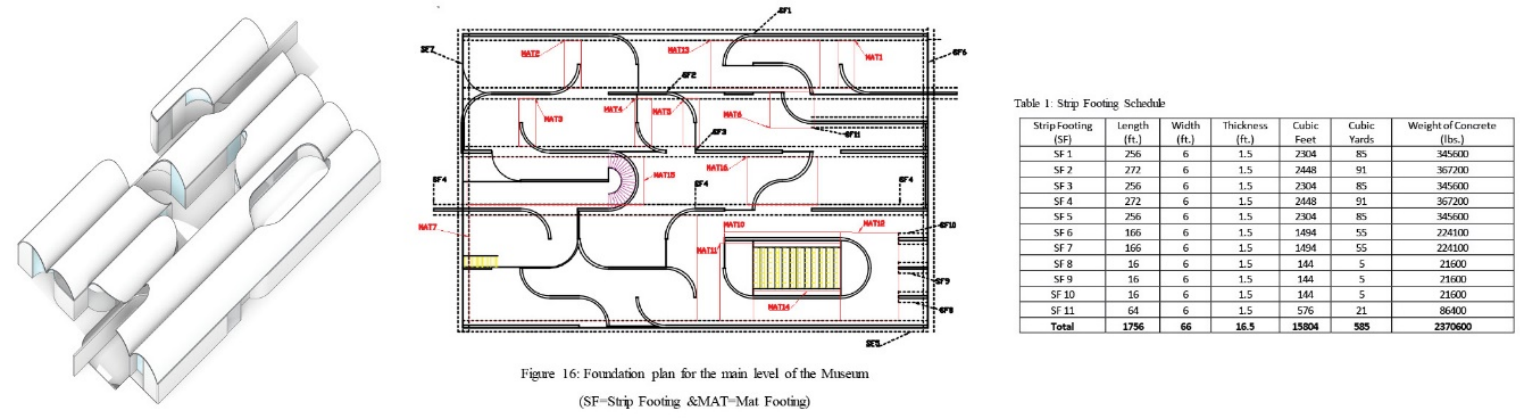

Figure 2: Student Project - "Rene Magritte Art Museum” (RMAM)

Architectural Design (left image) and Structural Analysis (right images). Students: Trevor Kaufman (A) / Abraham Mercado (CE), Aneesh Sreedhar (CET)

\section{Survey Results- Students' Perceptions}

Students were asked to take the survey at the very beginning of the project ( $1^{\text {st }}$ cycle) and again at the end of the quarter ( $2^{\text {nd }}$ cycle). In the first benchmark survey ( $1^{\text {st }}$ cycle), 16 Architecture students, 16 CE students, and 3 CET students took the questionnaire; in the second survey, 11 Architecture students, 14 CE students, and 4 CET students took the survey. The age group of students varied from 21 to 39 years. More than half of the students in both disciplines had at least 3-6 months of work experience (Figure 3). Seventy seven percent of the students were male and 33\% were female. The following sections describe the results of the survey starting with the students' perceived work interaction with each other, perceptions about the roles of the various disciplines, and finally their overall project experience and challenges they have encountered during the course of the project.

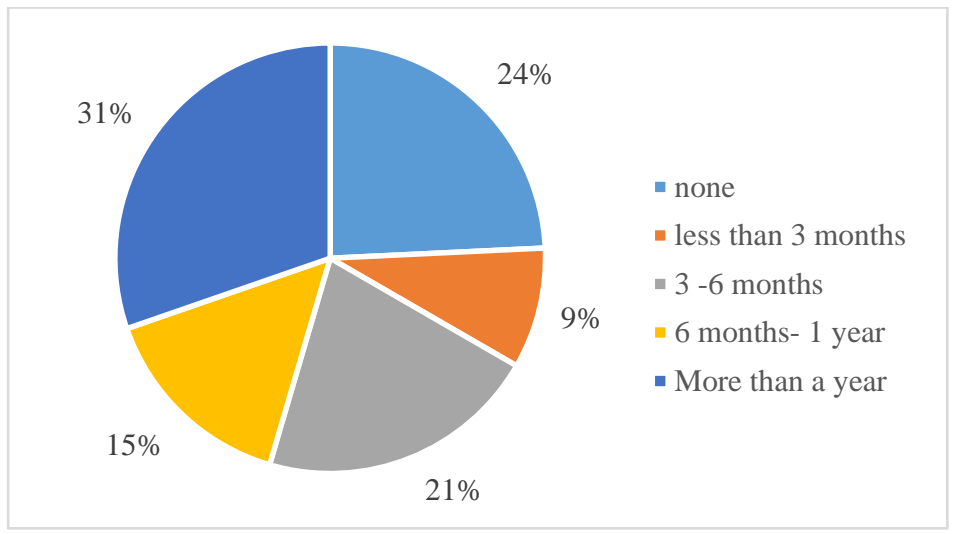

Figure 3: Students’ Industry Experience

\section{Work Interaction Questions}

This section reports the results of the questions that were asked to all students. When students were asked to rate their perception of resolution of conflicts between architects, designers, and contractors, from 1 to 5 (with 1 being extremely negative to 5 being extremely positive), 
Architecture and CE students had more optimistic perception of conflict resolution (Mean= 3), compared to CET students (Mean $=2$ ). A decrease in overall students' perception, in all disciplines of conflict resolution difficulty, is shown in Figure 4a (Architecture students dropped to a Mean of 2.33, CE to 2.46, while CET students to 1.67). When students were asked to rate their perception of whether they think conflicts will be resolved in their favor before going to court, from 1 to 5 (with 1 being always to 5 being never), Architecture students were more confident that conflicts will be resolved in their favor followed by CE students, then CET students in both surveys, showing an increase in the confidence level of the CET students only, by the second survey (Figure $4 \mathrm{~b})$. This might be related to the experience the students went through during the first quarter to achieve all disciplines' goals, as well as the discussions and debates they had which resulted in them being less optimistic about dispute resolution.

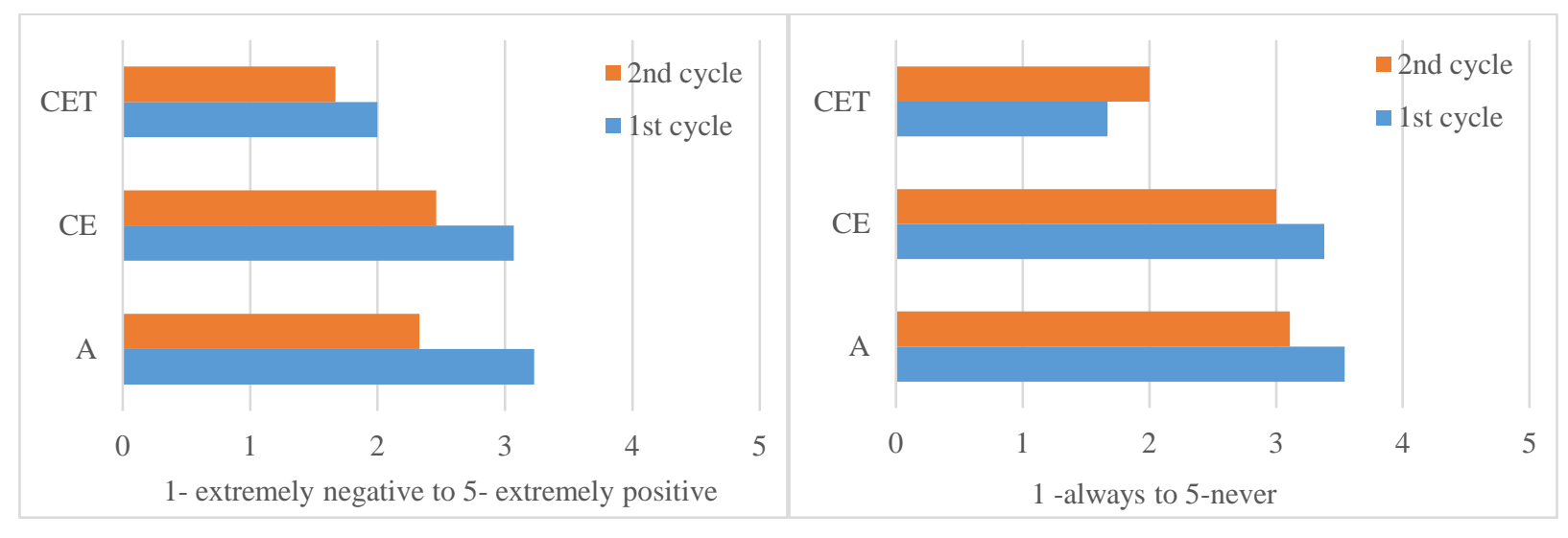

(a) Resolution of conflicts between designer and contractor are usually:

(b) How often do you think conflicts will be resolved in your favor before going to court?

Figure 4: Students’ perception of conflicts with other disciplines

When students were asked to prioritize a list of priorities on a project from 1-5 (with 1 being most important and 5 being least important), it was seen that in the two consecutive surveys, all students ranked 'owner satisfaction', as the first priority. The second priority differed based on discipline, with Architecture students' second priority being the architectural concept, while 'my employer/company requirements' being second for CE and CET students. CET students changed their second priority to 'high quality of material/workmanship' in the second survey. The interesting observation was that CE and CET students both rated 'architectural concept' as the least priority in both first and second surveys. An explanation for this might be that the architectural design process remains largely invisible to the other disciplines and the 'architectural concept' might be perceived as an obscure and intangible idea that is outside of the project. Architecture students, in contrast, are trained to think in concepts and encouraged to translate these concepts to all areas - including structures, materials, and systems. It is the architects' responsibility to communicate ideas and concepts to others - and this is an area that, in our study, might need improvement. Ultimately, when all disciplines involved understand the conceptual direction and see themselves as co-authors, the projects will have more chances to succeed.

When all groups were asked to select their preferences in terms of working with their own profession, other disciplines, or no one on the job site, both CE and CET students showed no major 
difference in preferring to work either way, with same discipline preference scoring a little higher for CE students (Figure 5). Architecture students showed a preference in working with other disciplines compared to the other two groups. As for the advantages and disadvantages of working with different disciplines, all disciplines listed "knowledge of topics I would unlikely learn about in my field" as their highest ranked. CET students equally also listed "learn how to communicate and explain with someone who doesn't have my background”. As for the disadvantages, all groups agreed that "having different priorities" is the major disadvantage with working with other disciplines.

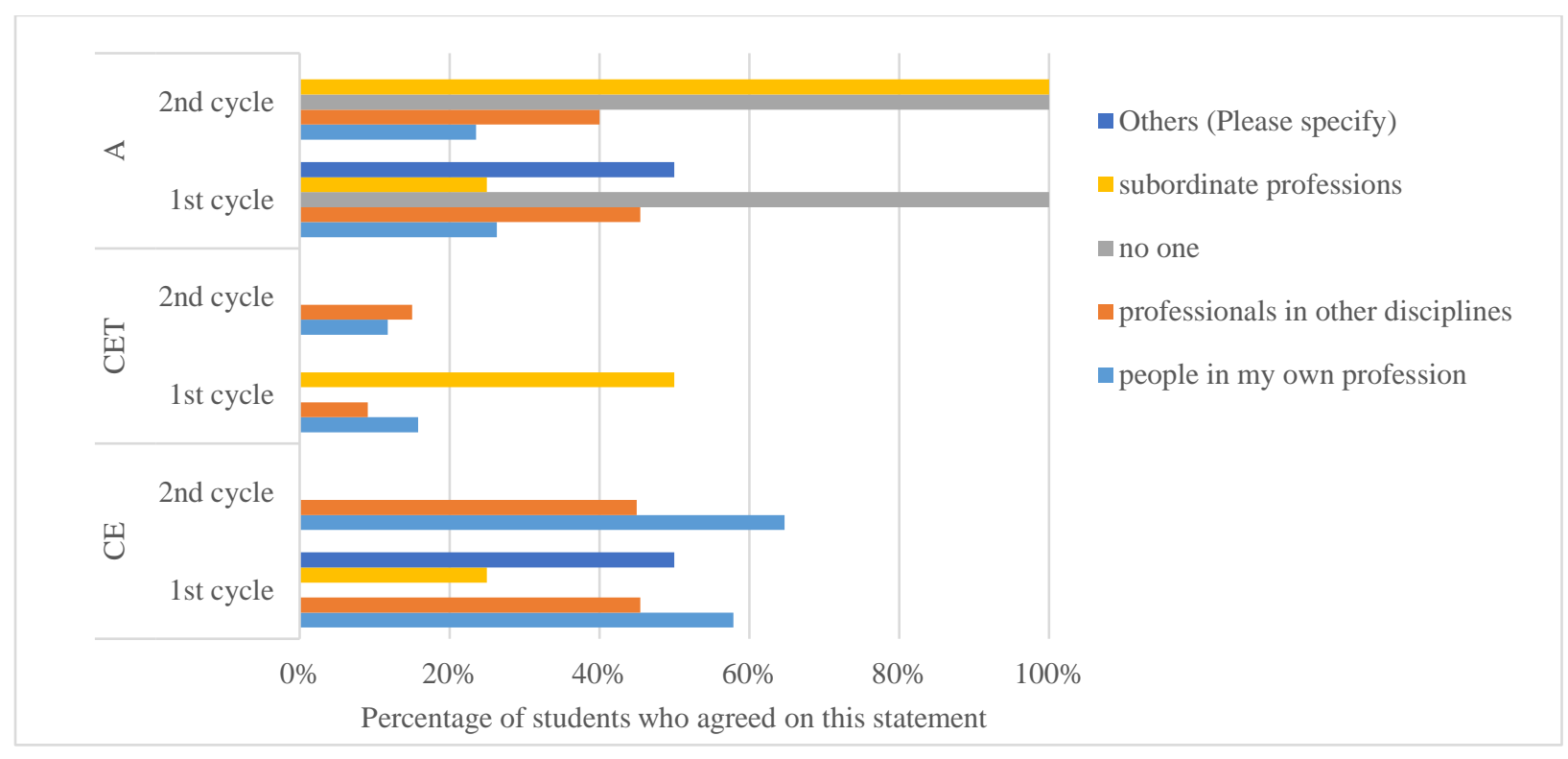

Figure 5: Students' preference to work with which disciplines

On being asked how often students expect to work with other disciplines, from 1 being never to 5 being always, CET students reported expecting to work with architects between never to sometimes (Mean =1.7), which increased to a Mean of 2.33 in the second cycle (Figure 6). This showed that students' interaction has affected their understanding of how they will interact with the architect in real life projects of this nature. CE students reported a higher average compared to CET students (Mean = 2.8). As for CET students' expectation working with civil engineers, CET students reported an interesting response from never to sometimes (Mean=1.5), with Architecture students showing a slighter higher average (Mean $=1.9$ ), that increased from the first to the second survey. As for Architecture students, a higher average was reported for their interaction with the civil engineers (Mean=2.8), compared to CET (increased from a Mean of 1.67 to 2.33).

When students were asked how much they expect to agree with other disciplines from never being 1, to always being 5, CE and Architecture students showed a consistent reporting in both surveys from sometime to half the time (Mean range between 2.4 and 3.33). While CET showed a drop in their perception with agreeing with both disciplines, with agreement with civil engineers dropping from a Mean of 3.33 to 2.67, and agreeing with architects from a Mean of 4 to 3. This might manifest CET students showing more disagreements with Architecture students, compared to CE students and Architecture students. The explanation for this could lie in the compressed project schedule for the project. Architecture students might have felt pressured by the CET students to 
produce quantifiable results at a very early stage in the process, when the project was still in development and constructability concerns felt premature. This finding might also be symptomatic for the fact that each discipline, primarily, follows their own agenda, which might be overcome by a more integrated approach, advocated by this study.

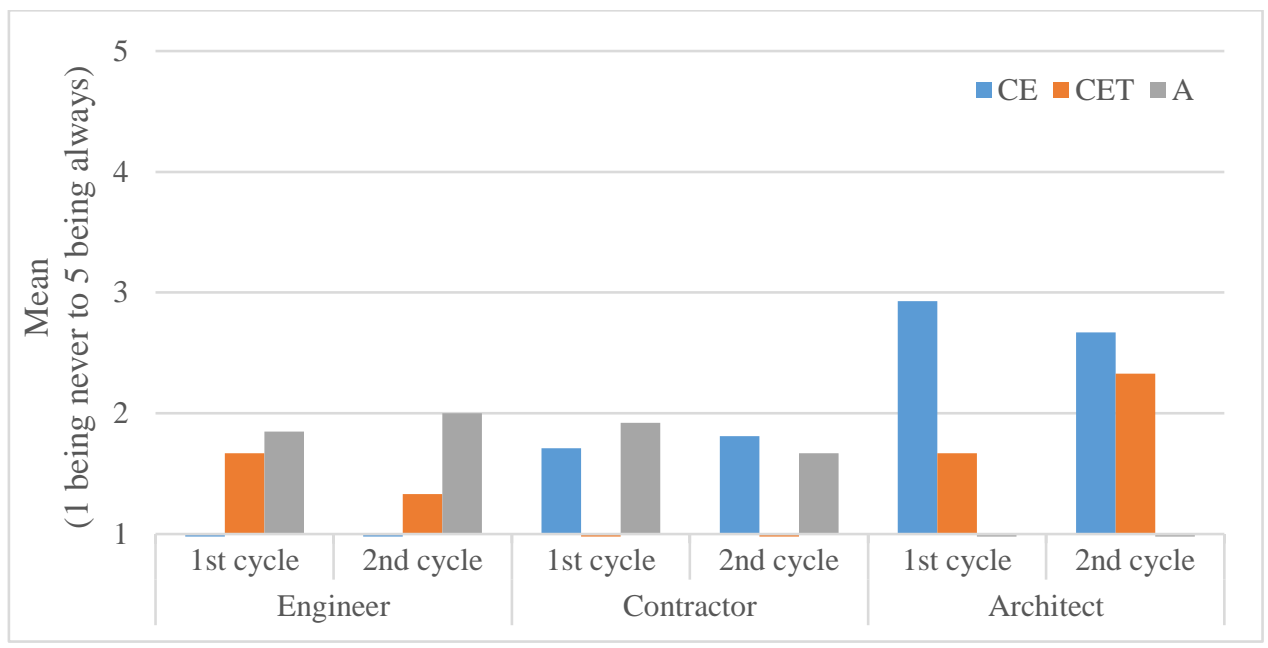

Figure 6: Students’ perceptions of how often they expect to work with each other

For CET students' perceptions of both civil engineers and architects, the highest ranked perception was their ability in recognizing errors in design and construction, and to make informed decisions. As for the $\mathrm{CE}$ and Architecture students, they both perceived contractors as being very knowledgeable of the construction methods. CE students thought architects were able to communicate effectively with most disciplines and are able to make informed decisions. When asked about their biggest concern when working with the other discipline, CET students reported not understanding the construction process, schedule, or cost as the highest concern, when working with both the civil engineers and architects. CE students' biggest concern working with contractors is that they would blame civil engineers for their own mistakes, and that they only care about money. Their concern regarding architects was primarily not caring about structural efficiency, and by the second survey the highest ranked was 'not understanding the building process.' It was interesting to see the increase in the number of CE students caring about the building process by the second survey. As for Architecture students, their major concern working with civil engineers and contractors was not understanding their vision of the project, and not caring about innovation if it takes time. "Only caring about the money" also emerged as concern that Architecture students had about contractors.

\section{Perceptions about Architects}

There were interesting discrepancies observed between the various disciplines' perception of each other, as well as between the changes in the opinions from the first to the second survey. The most evident changes in perception throughout the project were observed about Architects. The major changes seen in the CE students' perceptions about Architects from the first to the second survey, were in the following statements which showed an increase in agreement level; (1) they design structural and nonstructural components of buildings (from 35\% to 100\%), (2) they do not usually visit the construction site (from 50\% to 100\%), (3) they mostly value a project in terms of cost effectiveness (from 0\% to 50\%), and (4) they do not consider clients' or users' needs (Figure 7). 
The percentage of CE students who thought 'Architects think that structure should be addressed after the schematic design is completed' decreased from $50 \%$ to $0 \%$. These changes in percentages shows a considerable level of CE students' understanding of the architect's roles and responsibilities compared to their initial understanding.

In line with CE students, CET students' major increase in agreement was seen in the statement regarding Architects thinking that structure should be addressed after the schematic design is completed (13\% to 100\%). CET students also mostly changed their minds about Architects visiting the construction site, which dropped from $50 \%$ to $0 \%$ of the students, in agreement with this statement in the second survey. Considerable changes were seen in the data reported by the Architecture students of their own agreement with their roles and responsibilities. It was very interesting to observe how the architects' perception of their own role changed, for example after having none of the Architecture students in agreement with the statement that 'Architects do not usually visit the construction site', 50\% of the Architecture students agreed with this statement in the second survey. In addition, a decrease in the agreement with these statements was also observed; (1) Architects mostly value a project in terms of structural efficiency (from $62 \%$ to $0 \%$ ); (2) Architects assist both Civil and Construction Engineers during construction (from 57\% to 0\%); (3) Architects design structural and nonstructural components of buildings (from $53 \%$ to $0 \%$ ); and (4) Architects like to collaborate with many different disciplines (from $86 \%$ to $33 \%$ ).

\section{Perceptions about Civil Engineers}

Figure 8 shows that the changes in perceptions about Civil Engineers were less significant than the ones observed for Architects. A major increase in CE students' agreement was observed on the statement regarding Civil Engineers thinking that Construction Engineers work for them (increase from $0 \%$ to 33\%). This was also in line with the CET students observed trend (increase from $0 \%$ to $33 \%$ ) and was contrary to the trend observed by the Architecture students, which dropped in agreement from $100 \%$ to $33 \%$. Less CE students in the second survey reported that Civil Engineers mostly value a project in terms of construction time (dropped from $38 \%$ to $0 \%$ ). Also, none of the $\mathrm{CE}$ students agreed by the second survey that Civil Engineers do not usually visit the construction site (dropped from $66 \%$ to $0 \%$ ), as well as CET students, which dropped from $33 \%$ to $0 \%$, showing a better understanding of their roles in a DB project. This was contrary to the trend observed by the Architecture students, who agreed more (from 0\% to 100\%) that Civil Engineers do not visit the site. CET students showed a major increase in agreement on the statement that 'Civil Engineers think that architects work for them' (0\% to 100\% increase). This could be due to the demanding environment the CE students were placed in to request conceptual designs from the architects within a time constraint. Generally, Architecture students showed a somehow different trend compared to the CE and CET students in terms of their agreement about Civil Engineer responsibilities and roles statements. 

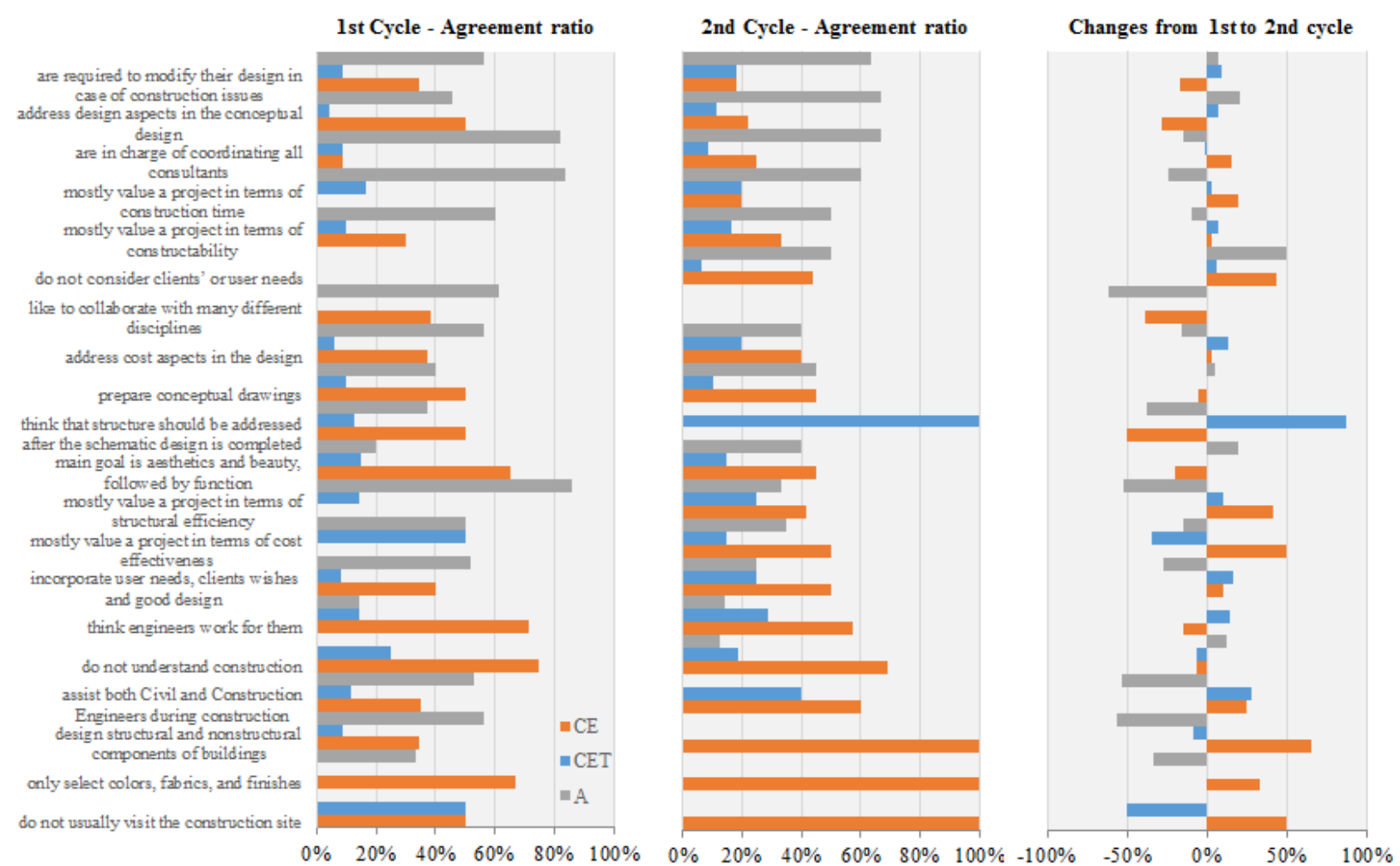

Figure 7: Which statements are true about Architects? (\% respondents agreeing)

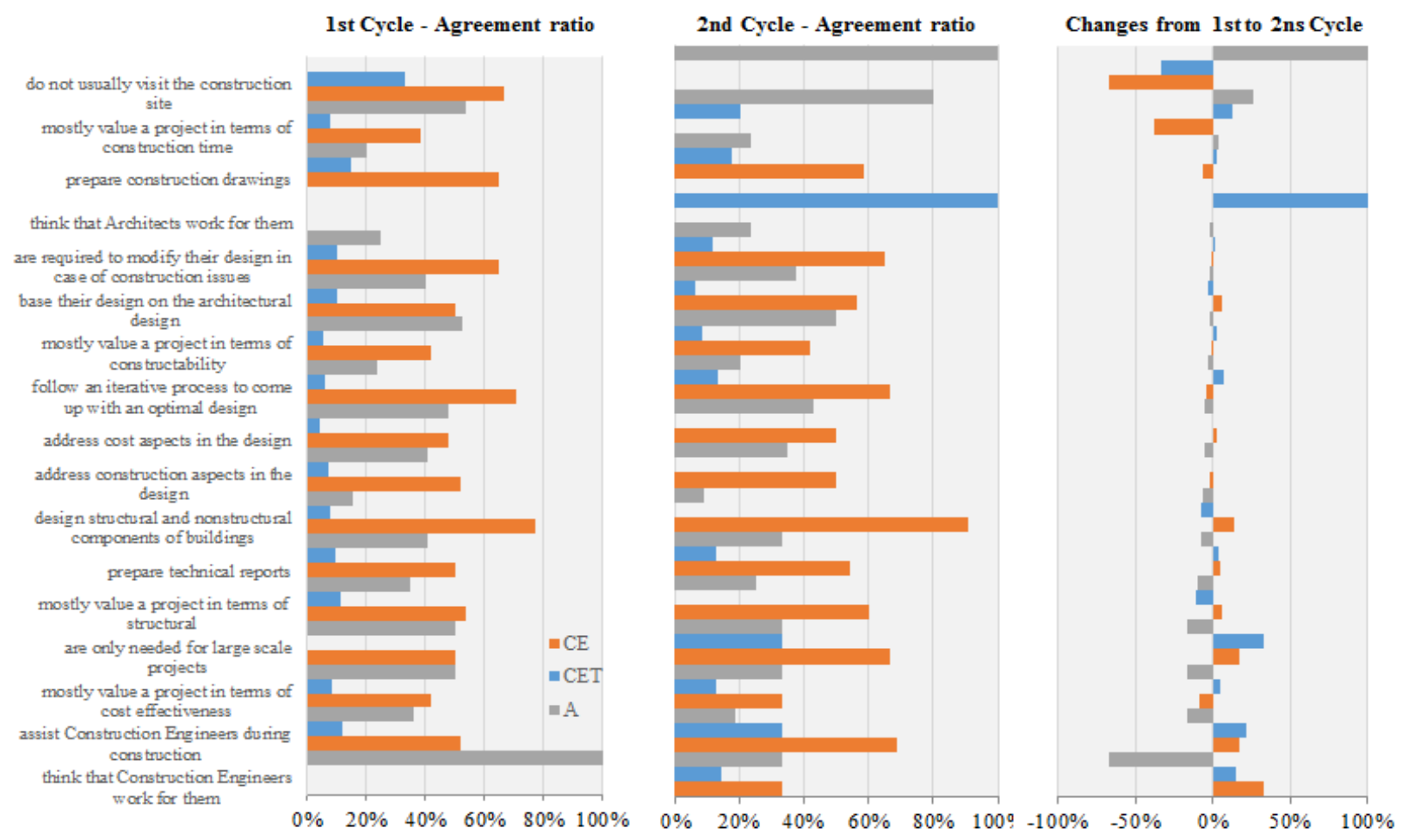

Figure 8: Which statements are true about Civil Engineers? (\% respondents agreeing) 


\section{Perceptions about Construction Engineers}

As seen in Figure 9, the lowest changes in perception were observed about Construction Engineers. The major changes observed in the CE students' perceptions from the first to the second survey were in the following statements about Construction Engineers; (1) "They mostly modify projects after revision of reports drawings", dropping from $84 \%$ to $50 \%$ in the second survey, (2) "They mostly work on site", dropping from 75\% to 55\%, and (3) "Construction Engineers mostly value a project in terms of structural efficiency", increasing from $0 \%$ to $30 \%$. This third change was also reported by the Architecture students, where an increase was observed (from 33\% to 55\% of the Architecture students agreeing that Construction Engineers value the project's structural efficiency. This is a very interesting change as it shows that both Architecture and CE students got a better understanding of the roles of construction engineers not being restricted to the site, and that they as well value the project's structural efficiency.
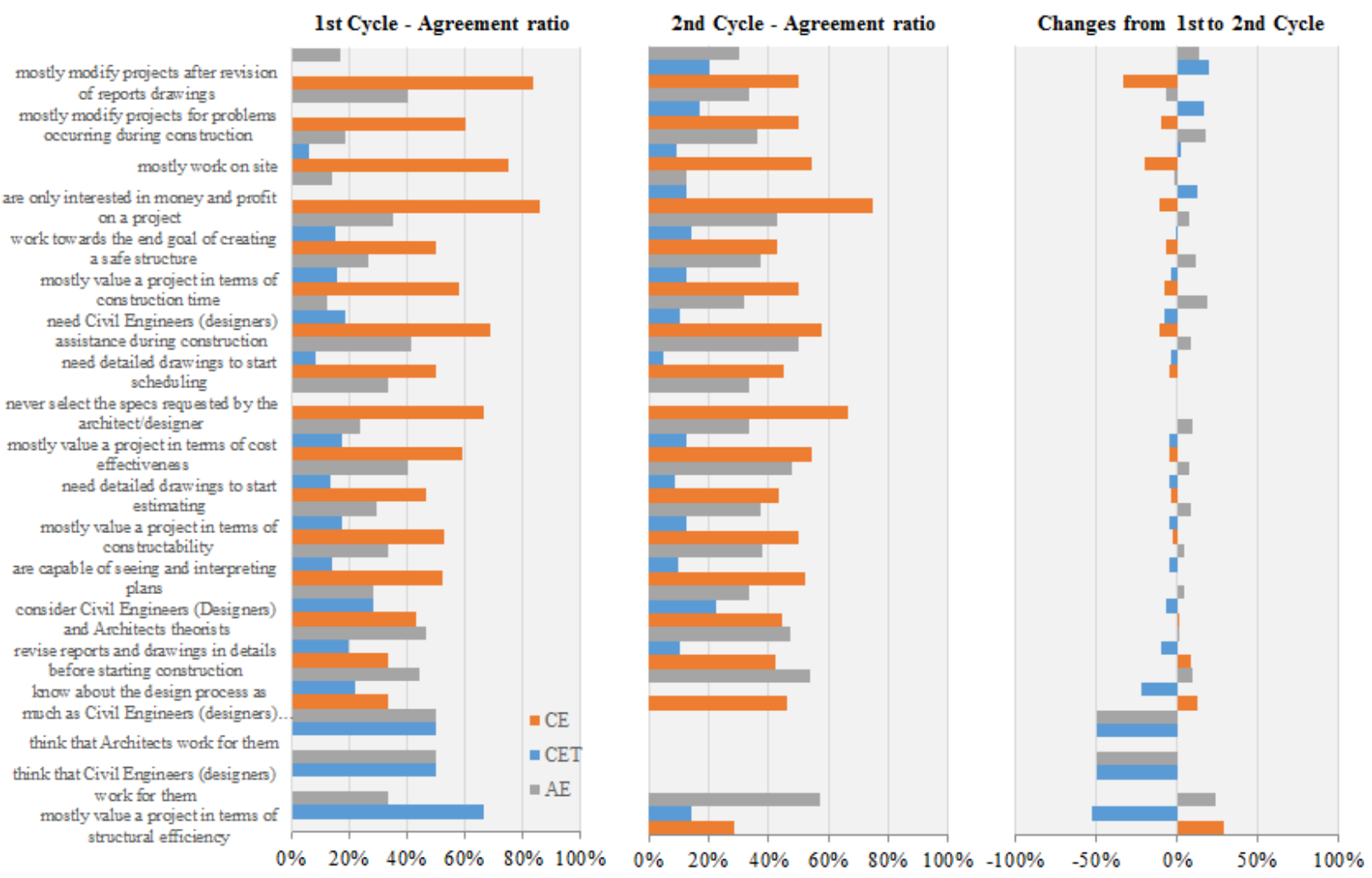

Figure 9: Which statements are true about Construction Engineers? (\% respondents agreeing)

The value of structural efficiency was also interesting from the perspective of the CET students, with $66 \%$ of them thinking they value structural efficiency, and then this number decreasing to $15 \%$ in the second survey. This is an interesting change that might have happened given CET students are now comparing their priorities to CE students, and realizing that their priorities are minimally geared towards structural efficiency. This type of change in both the CE and Architecture student group compared to CET students' perceptions shows a convergence in thoughts between the two disciplines after working for 3 months collaboratively. Another interesting change was how after 50\% of the CET students thought that both Civil Engineers and Architects worked for them, all changed their perceptions that they didn't (drop from 50\% to 0\%). 
This was the same change observed for the Architecture students who thought the same about construction engineers, and all changed their mind (50\% to 0\%). This illustrates the idea that the collaborative work environment reinforced in the project between different disciplines represents an attempt to reach common goals (class deliverables). Architecture students also changed their perception, reporting an increase regarding Construction Engineers needing Civil Engineers' assistance during construction from $12 \%$ to $31 \%$. This also shows that Architecture students are increasing their knowledge and awareness of the advantages of the involvement of Civil Engineers in the construction process.

In terms of comparing the various disciplines, Architecture and CE students started with considerable differences in perceptions about the role of Construction Engineers and then showed convergence in their opinions from the first survey to the second survey (such as working on site and believing that Construction Engineers think that Architects work for them). However, some perceptions of the Architecture and CE students still didn't change from the first to the second survey, such as 'Contractors being only interested in money and profit on a project', with $75 \%$ of the CE students reporting it in the second survey, compared to only 13\% Architecture students.

\section{Feedback received from students on the project and discipline interaction}

The students were asked a few open-ended questions regarding their experience, major challenges and conflicts they experienced or anticipate to experience at different stages of the project. Most of the comments received from the students followed positive themes, such as "learning from other disciplines" and "exposure to a real-life experience". For example, a CE student noted, "My experience thus far has been great. I have learned a lot about Construction Engineering and Architecture. Architects have really impressed me with their imagination and creativity. Most engineers would love to design traditionally and by the codes, while Architects love to be out of the box and do non-traditional designs, which, don't get me wrong, is not bad, just might not be practical at times. Overall, I have been impressed with their performance."

On the other side, a CET student stated, "The experience in this senior project has been quite challenging in a positive manner. Currently, the work is being mostly done by the architecture students but being able to contribute knowledge from the civil engineering and construction engineering fields is a rewarding experience...." They were also "...afraid architects [would] make a difficult design choice that will bump up the price of the project."

An Architecture student described the experience as "... interesting and helpful to have students from other disciplines give their feedback. We are usually so design-driven that, at times, we may not realize how "impossible" our project may be." Another Architecture student also stated, "This integrated project has been very beneficial for us. Architects and engineers work together in the real world. Allowing us to collaborate and work with other students has allowed us to have a more successful project in regards to both design and structural aspects of the project."

Lack of coordination, miscommunication, and different expectations were the biggest challenges quoted by students from all three disciplines. For example, a CE student commented, "...anticipating what other parties are capable of, willing to do, and need clarification on will make the communication between all parties a lot easier. My experience working in partnership this quarter has been difficult, largely due to a discrepancy in understanding of what the 
expectation of ourselves and of others ought to be. I expect better communication and more experience with other fields will help."

In terms of style of work, a CE student noted, "Architects tend to work slowly and make large sweeping changes that impact the structural design on short notice." A CET student commented, "The design-build project experience was a challenging undertaking for this fall quarter. It was definitely a challenge to coordinate and meet with all parties involved. It was clearly noticeable that the disciplines work at different paces, and it was a challenge to produce deliverables at the level of detail we needed or discovered that we needed...", and that "... it's hard to understand each other amongst different disciplines, as we don't really speak the same technical language."

A very interesting comment by an Architecture student citing creativity stated, "Overall, the experience was positive but I would recommend that the engineers not be afraid to be creative and innovative in order to solve the structural dilemmas us architecture students are great at creating."

Students were also asked to state the common stereotypes of their profession. CE students stated they are known to be poor at communicating, not concerned with aesthetics or construction schedule, "think our designs are perfect", are too theoretical, and "don't know how to be on a job site". On the other side, CET students' common stereotypes included not knowing any engineering/design work at all, only caring about budget, and not being very knowledgeable about the aesthetic and structural design of a building. Architecture students, on the other hand, thought they were perceived as egotistical and arrogant and only care about design and aesthetics, but do not understand construction.

\section{Conclusions}

This paper presented a new educational model that was developed to provide students in Architecture, Civil, and Construction Engineering an integrated professional experience, in line with contemporary trends of disciplines' integration in the construction industry, and to reap the potential benefits that arise from shared educational goals between different technical areas. The model encompassed coordination between an existing Architectural class and the CE and CET senior project class. The senior project was set up to mimic an IPD process that simulates the complete development of a commercial building, from conceptual design to construction. To assess the students' experience, three main tools were used that included (1) instructors' observations of the challenges faced by the students, (2) evaluation of the students' products, and (3) surveys delivered to the students to monitor the evolution of the mutual perception of their roles during the project.

Results of the three assessment tools show that the module was able to present the students with a real-life valuable experience, encompassing both the integrative learning experience, as well as the challenges faced. Instructors reported that during the development of the projects, there were instances where Architecture students completely changed their designs after a few weeks, and frustrated engineering students had to start all over, mirroring the cliché of architects who continuously change their projects and engineers who want to fixate the project as soon as possible. Students also reported in the survey how, even though coordinating and understanding other disciplines' priorities was challenging, it still provided them a real-life experience of what they would encounter in their careers. It was very interesting to monitor the evolution of the mutual 
perceptions of their roles during the project with students either gaining a better understanding of each other's roles and priorities, or even of their own roles on the project. With the increasing use of integrated PDMs in the industry, this module presents a valuable platform for students from different disciplines to interact and learn from each other and provides them an eye-opening experience on what to expect in their future careers as they interact with other disciplines.

The limitations of the project were that a schedule that reflected real-life project phase durations could not be implemented, due to the constraints of the academic schedule. This led to slightly skewed and biased responses (the perception that Architects worked for Construction Engineers, or that Construction Engineers mainly cared about money). The compressed schedule also meant that timing for deliverables was accelerated (for example, structural concepts and cost estimates were requested by instructors in absence of complete architectural designs). This put pressure on students of all three disciplines - Architecture students because they felt pressured to finish designs, CE and CET students because they felt they did not have enough material to work with to provide accurate structural concepts and cost estimates. However, the overall positive reaction from students, together with the high quality of their projects, means that the benefits of the project outweighed its shortcomings, and students gained an understanding of the collaborative process that, in the academic setting as much as in real life, is organic and not always straightforward.

\section{References}

1. Yates, J. K., and J. A. Smith. "Global legal issues for engineers and constructors," Journal of Professional Issues in Engineering Education and Practice, Vol. 133, no. 3, 2007, pp. 199-209.

2. Konchar, M. and V. Sanvido. "Comparison of U.S. Project Delivery Systems," J. Construction Engineering and Management., Vol. 124, no. 6, 1998, pp. 435-444.

3. Design Build Institute of America (DBIA). History of DBIA State Advocacy. Available at: http://www.dbia.org/advocacy/state/Pages/default.aspx, n.d. [Accessed September 2014].

4. Rangel, Bárbara., Guimarães, Ana Sofia., Vaz Sá, Ana., and Alves, Fernando Brandão. "Integrated design concept in civil engineering education." International Journal of Engineering Education, v 32, no. 3, 2016, p 1279-1288.

5. Solnosky, Ryan., Parfitt, M. Kevin, and Holland, Robert J. "IPD and BIM-focused capstone course based on AEC industry needs and involvement," Journal of Professional Issues in Engineering Education and Practice, v 140, no. 4, 2014. 